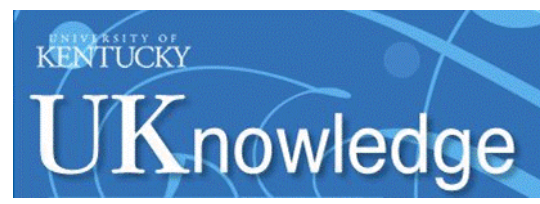

University of Kentucky

UKnowledge

\title{
Dynamic Range of Frontoparietal Functional Modulation is Associated with Working Memory Capacity Limitations in Older Adults
}

Jonathan G. Hakun

The Pennsylvania State University

Nathan F. Johnson

University of Kentucky, nathan.johnson@uky.edu

Follow this and additional works at: https://uknowledge.uky.edu/rehabsci_facpub

Part of the Cognitive Neuroscience Commons, and the Rehabilitation and Therapy Commons

Right click to open a feedback form in a new tab to let us know how this document benefits you.

\section{Repository Citation}

Hakun, Jonathan G. and Johnson, Nathan F., "Dynamic Range of Frontoparietal Functional Modulation is Associated with Working Memory Capacity Limitations in Older Adults" (2017). Physical Therapy Faculty Publications. 105.

https://uknowledge.uky.edu/rehabsci_facpub/105

This Article is brought to you for free and open access by the Physical Therapy at UKnowledge. It has been accepted for inclusion in Physical Therapy Faculty Publications by an authorized administrator of UKnowledge. For more information, please contact UKnowledge@lsv.uky.edu. 


\section{Dynamic Range of Frontoparietal Functional Modulation is Associated with Working Memory Capacity Limitations in Older Adults}

\section{Digital Object Identifier (DOI)}

https://doi.org/10.1016/j.bandc.2017.08.007

Notes/Citation Information

Published in Brain and Cognition, v. 118, p. 128-136.

(C) 2017 Elsevier Inc. All rights reserved.

This manuscript version is made available under the CC-BY-NC-ND 4.0 license https://creativecommons.org/licenses/by-nc-nd/4.0/.

The document available for download is the author's post-peer-review final draft of the article. 
Published in final edited form as:

Brain Cogn. 2017 November ; 118: 128-136. doi:10.1016/j.bandc.2017.08.007.

\title{
Dynamic Range of Frontoparietal Functional Modulation is Associated with Working Memory Capacity Limitations in Older Adults
}

\author{
Jonathan G. Hakun ${ }^{\mathrm{a}}$ and Nathan F. Johnson ${ }^{\mathrm{b}}$ \\ aDepartment of Psychology, The Pennsylvania State University, State College, PA 16801, USA \\ bDepartment of Rehabilitation Sciences, Division of Physical Therapy, University of Kentucky, \\ Lexington, KY 40536, USA
}

\begin{abstract}
Older adults tend to over-activate regions throughout frontoparietal cortices and exhibit a reduced range of functional modulation during WM task performance compared to younger adults. While recent evidence suggests that reduced functional modulation is associated with poorer task performance, it remains unclear whether reduced range of modulation is indicative of general WM capacity-limitations. In the current study, we examined whether the range of functional modulation observed over multiple levels of WM task difficulty (N-Back) predicts in-scanner task performance and out-of-scanner psychometric estimates of WM capacity. Within our sample (6077 years of age), age was negatively associated with frontoparietal modulation range. Individuals with greater modulation range exhibited more accurate N-Back performance. In addition, despite a lack of significant relationships between N-Back and complex span task performance, range of frontoparietal modulation during the N-Back significantly predicted domain-general estimates of WM capacity. Consistent with previous cross-sectional findings, older individuals with less modulation range exhibited greater activation at the lowest level of task difficulty but less activation at the highest levels of task difficulty. Our results are largely consistent with existing theories of neurocognitive aging (e.g. CRUNCH) but focus attention on dynamic range of functional modulation as a novel marker of WM capacity-limitations in older adults.
\end{abstract}

\section{Keywords}

fMRI; modulation; working memory capacity; N-Back; aging

Correspondence: Jonathan G. Hakun, Department of Psychology, The Pennsylvania State University, University Park, PA 16802-3104, Phone: (814) 867-2441, jgh5196@psu.edu.

Publisher's Disclaimer: This is a PDF file of an unedited manuscript that has been accepted for publication. As a service to our customers we are providing this early version of the manuscript. The manuscript will undergo copyediting, typesetting, and review of the resulting proof before it is published in its final citable form. Please note that during the production process errors may be discovered which could affect the content, and all legal disclaimers that apply to the journal pertain. 


\section{INTRODUCTION}

Human aging is associated with declines in working memory (WM) and alterations in brain function (Bopp \& Verhaeghen, 2005; Braver \& West, 2008; Cabeza \& Dennis, 2012; Drag \& Bieliauskas, 2010; Grady, 2012; Lustig, Hasher, \& Zacks, 2007; Park \& Hedden, 2001; Reuter-Lorenz \& Park, 2010). During WM task performance older adults tend to exhibit similar spatial patterns of activation to younger adults, but show altered patterns of activation modulation including increased response magnitude at low levels of task difficulty ("overactivation") and a more rapid approach of asymptotic activation levels as task difficulty increases (Cappell, Gmeindl, \& Reuter-Lorenz, 2010; Mattay et al., 2006; Nagel et al., 2011; Schneider-Garces et al., 2010). While these modulatory patterns have advanced neurocognitive compensation theory (e.g. the compensation-related utilization of neural circuits hypothesis; CRUNCH; Reuter-Lorenz \& Cappell, 2008), recent evidence suggests that altered modulation patterns, such as a reduced modulatory range, may track closely with individual and age psychometric differences in WM function (Schneider-Garces et al., 2010).

WM processing is associated with activation of regions throughout frontoparietal cortices (e.g., bilateral dorsal and ventral prefrontal cortices, anterior cingulate cortex, superior and lateral parietal cortices; Nee et al., 2013; Owen, McMillan, Laird, \& Bullmore, 2005; Rottschy et al., 2012; Wager \& Smith, 2003). Regions throughout this network tend to exhibit an orderly parametric response to experimental manipulations of task difficulty including manipulation of set-size (\# of items to be maintained in WM) and judgment difficulty (\# of items to search through in continuous performance WM tasks; Owen et al., 2005; Rottschy et al., 2012). In addition, asymptotic levels of activation have been observed across various neuroimaging modalities (e.g., EEG, fMRI) at set-sizes that match behavioral estimates of WM span (\# of items a participant is estimated to be able to maintain in WM; Linden et al., 2003; McCollough, Machizawa, \& Vogel, 2007; Song \& Jiang, 2006; Todd \& Marois, 2004, 2005; Vogel \& Machizawa, 2004; Xu \& Chun, 2006).

Age-associated reductions in frontoparietal functional modulation range have been observed in studies of WM function involving span tasks (e.g. memory search task; Cappell et al., 2010; Schneider-Garces et al., 2010) and continuous performance task paradigms (e.g. NBack task; Kaup, Drummond, \& Eyler, 2014; Mattay et al., 2006; Nagel et al., 2011). It remains unclear whether declines in modulation range are due to general capacity limitations or distinct task-related impairments, as few studies have linked in-scanner modulation range with out-of-scanner psychometric measures. It is also unknown whether functional modulation range, like other neurocognitive functional markers such as over-activation (Cabeza, Anderson, Locantore, \& McIntosh, 2002; Colcombe, Kramer, Erickson, \& Scalf, 2005; Dolcos, Rice, \& Cabeza, 2002), differentiates between high and low performing older adults. Based on recent evidence from meta-analyses showing that WM paradigms such as the N-Back and span tasks involve an overlapping, core frontoparietal network (Rottschy et al., 2012), we hypothesized that frontoparietal modulation range may reflect individual differences in WM capacity (WMC) limitations among older adults. 
$\mathrm{WM}$ is the stage in information processing theories of human cognition associated with short-term representation of active memory traces (Baddeley, 2003). WM is capacity-limited and generally limited to only a few units/chunks of information (Cowan, 2005, 2010; Luck \& Vogel, 2013; Miller, 1956; M. L. Turner \& Engle, 1986). However, considerable individual differences exist in the amount of information that can be actively maintained in WM, particularly under conditions of distraction (Conway, Kane, \& Engle, 2003; Kane \& Engle, 2003). While short-term representation in WM is supported by separable storage units (e.g. visual vs verbal buffers; Baddeley \& Hitch, 1974), individual differences in WMC are thought to emerge primarily through differences in domain-general abilities associated with actively maintaining, updating, and retrieving memory traces (Alvarez \& Cavanagh, 2004; Barrouillet, Bernardin, \& Camos, 2004; Bays et al., 2009; Cowan, 1999, 2005; Engle, 2002; Kane \& Engle, 2003; Luck \& Vogel, 2013; Oberauer, Lewandowsky, Farrell, Jarrold, \& Greaves, 2012; Unsworth, Fukuda, Awh, \& Vogel, 2014). Such a domain-general component of WM has been corroborated by functional imaging evidence showing overlapping activation patterns across verbal and visual WM task conditions in the core frontoparietal network associated with span and N-back task performance (Rottschy et al., 2012). Domain-general declines in WM processing have been the focus of several theories of cognitive aging (Braver \& West, 2008; Hasher \& Zacks, 1988; Lustig et al., 2007) and may help explain declines across multiple domains of cognition (Braver \& West, 2008; Kennedy, Partridge, \& Raz, 2008; Lustig et al., 2007; Park et al., 1996; Park \& Hedden, 2001; Salthouse, 1990).

In the current study, we investigated domain-general WM function by examining composite estimates of frontoparietal functional modulation range and WMC through performance of visual and verbal versions of N-Back (in-scanner) and complex span tasks (out-of-scanner). Critically, previous research shows that performance on N-Back and span tasks is largely uncorrelated (sharing only a much as $2-5 \%$ variance; Kane, Conway, Miura, \& Colflesh, 2007; Redick \& Lindsey, 2013; Roberts \& Gibson, 2002). However, latent estimates of performance on N-Back and complex span tasks covering multiple stimulus modalities were shown to be highly correlated in a previous study (Schmiedek, Hildebrandt, Lövdén, Lindenberger, \& Wilhelm, 2009). Here we sought to determine whether functional modulation range in the core frontoparietal WM network, similarly, serves as an indicator of domain-general WMC in older adults.

Fifty-three participants between the ages of 60-77 years old participated in an fMRI scanning session where they performed visual and verbal N-Back task conditions and a separate cognitive assessment session where they completed visual and verbal complex span tasks (Operation Span and Symmetry Span). We first examined individual differences in functional modulation across levels of the N-Back task by fitting a parametric contrast to functional activation across all four levels of both task conditions (visual and verbal). After determining which regions scaled parametrically with increases in task demand we examined whether modulation range was associated with individual differences in conditional activation, performance during the N-Back task, and individual differences in psychometric WMC. 


\section{METHODS}

\subsection{Participants}

A total of 53 right-handed healthy older adults participated in the study $(24 \mathrm{M} / 29 \mathrm{~F}$; age range $=60-77$, mean age $=66.62$, age $\mathrm{SD}=4.15$ ). Written informed consent was obtained from each participant under an approved University of Kentucky Institutional Review Board protocol. Participants were recruited from the community and were financially compensated. Exclusionary criteria for the study included the following: color blindness, major head injury, stroke, neurological or psychiatric disorder, high blood pressure, diabetes, heart disease, the use of psychotropic drugs, and or the presence of metal fragments and/or metallic implants contraindicated for MRI. Two participants were excluded from analyses involving N-Back task performance due to missing data $(<70 \%$ of trials were recorded during 2-Back and 3-Back conditions).

\subsection{Materials and Procedure}

2.2.1 N-Back task-Participants completed a 4-level N-Back task (Compare, 1-Back, 2Back, 3-Back) that included verbal (letters) and visual (faces) task conditions. During the Compare task condition participants judged whether two stimuli presented side-by-side (either two letters or two faces) were the same or different. During the 1-Back condition, participants were asked to judge whether the item on the current trial matches the item presented one item back in history. Similarly, the 2-Back and 3-Back conditions involved the same procedure as the 1-Back but varied with respect to how far back in the trial history (2or 3-Back) comparisons were made (Figure 1). Responses were made using MRI compatible response button-boxes (one in each hand). Participants were asked to press the left button for "same" judgments and press the right button for "different" judgments. Participants were asked to respond as quickly and accurately as possible.

Task blocks were 40 seconds in duration ( 15 trials per block), and fixation periods were 17.5 seconds in duration. There were two runs. Each run began and ended with a fixation period (+ symbol presented centrally) and contained a total of 8 task blocks and 9 fixation periods. Each run contained two blocks of each N-Back level (including one block of each stimulus type). Each task block began with an instruction screen containing the task condition (e.g. "Compare", "1-Back") presented centrally for $2500 \mathrm{~ms}$. Following the instruction screen, stimuli were presented centrally for $2000 \mathrm{~ms}$ each, separated by $500 \mathrm{~ms}$ of fixation. Eight upper-case letters were included (B, F, K, H, M, Q, R, Y) in the verbal task and eight face stimuli were included in the visual task. Each face stimulus was a computerized drawing of a face containing only a circular face outline, eyes, eyebrows, and a mouth. Face stimuli each contained a different facial expression (based loosely on contemporary "emoji") and varied only in the length, curvature, or angle of the mouth and eye brow features (see Figure 1 for the complete set of faces). Each task block contained 4 target matching stimuli and 11 nonmatching stimuli. The order of task blocks was pseudorandomly assigned and kept consistent across participants. Task blocks within each run alternated between verbal and visual N-Back tasks. 
Task stimuli were generated by E-prime software (Psychology Software Tools, Inc, Pittsburgh, PA) and projected to a mirror mounted on the MRI head coil using an MRI compatible projector. Response time and accuracy for subject responses on each trial were recorded by the stimulus presentation program.

Prior to scanning, participants received task instructions along with 2 practice runs of each task condition before proceeding to the scanner. Participants were required to reach an accuracy criterion of $75 \%$ during Compare and 1-Back task practice. All participants reached this practice accuracy criterion.

2.2.2 Complex Span Tasks-Two automated complex span tasks (Operation Span and Symmetry Span) were administered together in a session separate from the scanning session. The Operation Span task measures the ability to store information in verbal working memory while processing additional information. Similarly, the Symmetry Span task measures the ability to store information in visual working memory while processing additional information. Each automated task contained self-guided instructions, practice, and timing parameters customized to the participant (for a full description of the development, parameters, and reliability of these automated procedures, see Conway et al., 2005; Redick et al., 2012).

Briefly, the Operation Span task involved memorizing a single letter at a time while performing interleaved arithmetic operations. After memorizing a set of letters and completing the interleaved arithmetic operations, participants were asked to recall all of the letters memorized throughout the current trial in order. Trials randomly varied in set-size. Set sizes (\# of total letters memorized) ranged from 3-7 with three repetitions of each set size throughout the task. The total number of item-operation pairs was 75 .

The Symmetry Span task involved memorizing highlighted locations in a $4 \times 4$ matrix one at a time while performing interleaved symmetry judgments on $8 \times 8$ mosaic pattern stimuli that were either symmetrical or non-symmetrical along the vertical axis. After memorizing a set of locations and completing the interleaved symmetry judgments, participants were asked to recall all of the spatial locations from the $4 \times 4$ matrices memorized throughout the current trial in order. Trials randomly varied in set-size. Set sizes (\# of total locations memorized) ranged from $2-5$ with three repetitions of each set size throughout the task. The total number of location-symmetry pairs was 42 .

Both Operation Span and Symmetry Span were scored according to the partial-trial scoring method (Conway et al., 2005). The partial-trial scoring method involves counting each item recalled in the correct order from memory regardless of whether all items within a trial were recalled. A composite estimate of WMC was calculated by averaging performance on the Operation and Symmetry Span tasks. In order to account for differences in total potential span scores, span scores for each task were first z-scored and then z-scores were averaged.

\subsection{Imaging Data Acquisition}

Imaging data were collected on a 3T Siemens TIM scanner at the Magnetic Resonance Imaging and Spectroscopy Center of University of Kentucky. Two types of images were 
collected for use in this study: 1) high-resolution T1-weighted image for functional image registration and 2) T2*-weighted images sensitive to the BOLD signal. High-resolution T1weighted images were collected using an MPRAGE sequence (TR $=2100 \mathrm{~ms}$; TE $=2.93$ $\mathrm{ms} ; \mathrm{FA}=12$ degrees; resolution $=1 \mathrm{~mm}$ isotropic). Functional images were collected using a T2*-weighted gradient echo-planar sequence $(\mathrm{TR}=2500 \mathrm{~ms}, \mathrm{TE}=30 \mathrm{~ms}, \mathrm{FA}=76$ degrees, $\mathrm{FOV}=224 \mathrm{~mm}^{2}$, matrix $=64 \times 64$, resolution $=3.5 \mathrm{~mm}$ isotropic, 33 interleaved slices).

\subsection{Functional Imaging Data Preprocessing}

Imaging data were preprocessed and analyzed using FMRIB's Software Library (FSL) and fMRI Expert Analysis Tool (FEAT; Jenkinson, Beckmann, Behrens, Woolrich, \& Smith, 2012). Functional data were brain-extracted (i.e. skull-stripped) and motion-corrected to the median functional image using b-spline interpolation (4 degrees of freedom). The resulting functional images were high-pass filtered (100 s/cycle) and spatially smoothed [6mm full width at half maximum (FWHM), isotropic]. The anatomical volume was brain-extracted and registered to standard space T1 MNI $2 \times 2 \times 2 \mathrm{~mm}$ template with FMRIB's Non-linear Image Registration Tool (FNIRT; Andersson, Jenkinson, \& Smith, 2007). Each participant's median functional image was co-registered to their anatomical volume and warped to standard space using the non-linear warping matrix generated by the transformation of anatomical volume to standard space (Andersson et al., 2007). All resulting functional images were interpolated to $2 \times 2 \times 2 \mathrm{~mm}$ resolution for group analysis in MNI standard space.

\subsection{Functional Imaging Single-Subject Analysis}

Functional data were first modeled at the individual subject-level by fitting a voxel-wise General Linear Model (GLM) to the BOLD data acquired for each run. The two runs were modeled separately and included task regressors for the visual and verbal Compare, 1-Back, 2-Back, and 3-Back blocks. Task regressors were modeled as a box-car function and convolved with a canonical double-gamma hemodynamic response function. Consistent with estimation of WMC, subject-level contrast maps for each level of the N-Back task were generated representing the average of visual and verbal $\mathrm{N}$-Back task conditions at each level (e.g. average of visual and verbal 1-Back). A linear parametric contrast $[-3,-1,1,3]$ was generated to detect regions that parametrically scaled in functional activation magnitude from Compare to 1 -Back to 2-Back to 3-Back, respectively. In addition, a mean activation contrast was generated estimating average activation level across all task conditions. Firstlevel contrast-maps for each N-Back condition, mean across all conditions, and parametric slope (the linear parametric contrast) from Compare to 3 -Back were passed to a $2^{\text {nd }}$-level fixed effects model. In the $2^{\text {nd }}$-level model, subject-level contrast-maps were averaged across the two runs.

\subsection{Functional Imaging Group Analysis}

Parametric slope contrast maps from the $2^{\text {nd }}$ level fixed effects model were entered into whole-group one-sample t-test where voxel-wise parametric increases in activation from the Compare to the 3-Back condition were explored. The whole-brain group-level parametric contrast was thresholded at voxel-wise FWE-corrected $\mathrm{p}<0.05$ (corresponding to voxel- 
level threshold of $Z>4.7$ ). Spherical ROIs (5mm radius) were centered on local peaks of clusters resulting from the one-sample t-test. Ten total ROIs were identified based on the peaks of clusters in frontal and parietal cortices (see Table 1). Subject-level parametric slopes, conditional means, and mean activation across all conditions for each ROI were estimated by calculating the average parameter estimate of all voxels falling within each spherical ROI mask. These parameter estimates were acquired from the individual results of the $2^{\text {nd }}$-level fixed effects model (where parameter estimates were averaged across runs). Frontoparietal slope and mean composites were created by first z-scoring the parameter estimates for each ROI obtained from the $2^{\text {nd }}$-level model and then averaging the $\mathrm{z}$-scores across all ten ROIs. fMRI analysis results were rendered using Surf Ice by Chris Rorden (https://www.nitrc.org/projects/surfice/).

\section{RESULTS}

\subsection{N-Back Performance}

Consistent with the imaging results, all behavioral analyses were conducted on average performance across visual and verbal N-Back conditions. The results of a $1 \times 4$ repeated measures ANOVA on accuracy indicated a significant main-effect of accuracy $(F(3,150)=$ 145.2, MSE $=0.731, \mathrm{p}<0.001)$. Results of post-hoc comparisons revealed a significant reduction in accuracy between the Compare and the 1-Back task conditions $(\mathrm{t}(50)=5.09, \mathrm{p}$ $<0.001), 1$-Back and 2-Back conditions $(\mathrm{t}(50)=7.91, \mathrm{p}<0.001)$, and 2-Back and 3-Back conditions $(\mathrm{t}(50)=5.55, \mathrm{p}<0.001 ;$ Figure $2 \mathrm{~A})$.

The results of a $1 \times 4$ repeated measures ANOVA on response time (RT) indicated a significant main-effect of RT $(F(3,156)=65.14, \mathrm{MSE}=597858.7, \mathrm{p}<0.001)$. Results of post-hoc comparisons revealed a significant increase in RT between the Compare and the 1Back task conditions $(\mathrm{t}(50)=-5.27, \mathrm{p}<0.001)$ and between 1-Back and 2-Back conditions $(\mathrm{t}(50)=-7.16, \mathrm{p}<0.001)$. No significant increase in RT was observed between the 2-Back and the 3-Back conditions ( $(50)=-1.26, p=0.21$; Figure $2 B$ ).

\subsection{WMC and N-Back Performance}

Performance on Operation Span $(\mathrm{M}=46.4, \mathrm{SD}=13.0)$ and Symmetry Span tasks $(\mathrm{M}=$ $19.2, \mathrm{SD}=6.8)$ was significantly correlated $(\mathrm{r}(53)=0.41, \mathrm{p}=0.003)$. Additional correlation analyses were run to examine whether WMC was related to performance during each condition of the N-Back task. The results of correlation analyses on accuracy revealed a significant correlation between WMC and accuracy during the Compare condition only $(\mathrm{r}(51)=0.30, \mathrm{p}=0.03)$. No significant correlation was observed between WMC and the 1Back $(r(51)=0.23, \mathrm{p}=0.10), 2-\operatorname{Back}(\mathrm{r}(51)=0.23, \mathrm{p}=0.10)$ and 3-Back conditions $(\mathrm{r}(51)=$ $0.05, \mathrm{p}=0.76)$. No significant relationship was observed between WMC and RT during the Compare $(\mathrm{r}(51)=-0.18, \mathrm{p}=0.20), 1-\operatorname{Back}(\mathrm{r}(51)=-0.24, \mathrm{p}=0.09), 2-\operatorname{Back}(\mathrm{r}(51)=-0.06$, $\mathrm{p}=0.69)$, or 3-Back $(\mathrm{r}(51)=0.01, \mathrm{p}=0.94)$ conditions.

\subsection{Functional Activation during N-Back}

The results of the group voxel-wise one-sample t-test performed on the parametric slope contrast revealed a significant linear increase in functional activation magnitude throughout 
frontal and parietal cortices. The regions that scaled positively with increase in N-back difficulty included dorsal and ventral lateral prefrontal cortex including bilateral anterior insulae (AI) and bilateral middle and inferior frontal gyri (MFG/IFG), anterior cingulate cortex (ACC), and posterior parietal cortex including bilateral intraparietal sulci (IPS) and dorsal precuneus (PREC; Table 1). See Figure 3 for results of the group-level parametric slope contrast and location of cluster peaks used for the ROI analysis.

\subsection{Parametric Slope and N-Back Conditional Activation}

Parametric slope estimates across the 10 ROIs were highly correlated (ranging from $0.39-0.84$, all p's < 0.004; $\mathrm{M}(r$-value $)=0.57, \mathrm{sd}(r$-value $)=0.09)$. Reliability analysis suggested that parametric slope estimates across the 10 ROIs were highly reliable (Cronbach Alpha $=0.93$ ), and therefore, a composite of parametric slope estimates across the 10 frontoparietal ROIs was constructed ("Frontoparietal Slope") for further analyses.

Individual differences in Frontoparietal Slope could emerge from a number of patterns of activation across levels of the N-Back task. For example, participants with overall shallower slopes may exhibit similar levels of functional activation during the easiest or most difficult task conditions while failing to modulate activation across task in a manner similar to participants with steeper slopes. In order to investigate how differences in Frontoparietal Slope were reflected in levels of conditional activation across the same ROIs we first conducted a median-split on Frontoparietal Slope, separating the sample into High and Low Slope groups.

After splitting the sample into High and Low Slope groups we compared mean functional activation magnitude across the 10 ROIs ("Frontoparietal Activation Magnitude") between groups at each level of the N-Back task. Note that a group $\times$ task condition interaction is statistically guaranteed by splitting the sample based on slope across task conditions. Therefore, only group contrasts at each level of the N-Back task were conducted to reveal the overall pattern of group differences as discussed above. Results of independent-samples t-tests on Frontoparietal Activation Magnitude revealed group differences during the Compare condition $(\mathrm{t}(51)=3.53, \mathrm{p}=0.001), 2$-Back condition $(\mathrm{t}(51)=-2.06, \mathrm{p}=0.045)$, and 3-Back condition $(\mathrm{t}(51)=-3.45, \mathrm{p}=0.001)$. No group difference was observed during the 1-Back condition $(\mathrm{t}(51)=0.73, \mathrm{p}=0.47)$. Overall, this pattern of group differences revealed that individuals with shallower slopes showed generally greater activation during the least difficult task condition (Compare) and less activation during the most difficult task conditions (2-Back \& 3-Back; Figure 4A).

\subsection{Frontoparietal Slope, N-Back Performance, Age, and WMC}

Results of correlation analyses of Frontoparietal Slope and performance on the N-Back revealed a significant correlation between Frontoparietal Slope and accuracy during the Compare $(\mathrm{r}(51)=0.35, \mathrm{p}=0.01), 1$-Back $(\mathrm{r}(51)=0.31, \mathrm{p}=0.03)$, and 2-Back conditions $(r(51)=0.28, p=0.046)$. No significant correlation was observed between Frontoparietal Slope and accuracy during the 3-Back condition $(\mathrm{r}(51)=-0.02, \mathrm{p}=0.91)$. No significant correlation between Frontoparietal Slope and RT was observed during any condition (all p's $>0.08$ ). 
The results of a correlation analysis on Age and Frontoparietal Slope revealed that Age was negatively correlated with Frontoparietal Slope $(r(53)=-0.28, p=0.04)$, suggesting that increases in Age were associated with a reduction in the range of functional activation observed across N-Back task conditions (Figure 5A). The results of a correlation analysis on Age and WMC revealed no significant relationship between Age and WMC $(\mathrm{r}(53)=-0.06$, $\mathrm{p}=0.68 ;$ Figure 5B).

Two analyses were conducted in order to address the central question of whether the range of functional modulation over levels of N-Back task difficulty was associated with individual differences in WMC. First, a significant positive correlation was observed between Frontoparietal Slope and WMC $(r(53)=0.30, p=0.03$; Figure 5C). Second, a multiple regression analysis was conducted on WMC entering Frontoparietal Slope as a predictor while controlling for individual differences in mean activation across task conditions and Age. Results of the multiple regression analysis revealed that Frontoparietal Slope was a significant predictor of WMC (standardized $\beta=0.35, \mathrm{p}=0.02$ ) while controlling for mean activation (standardized $\beta=-0.24, \mathrm{p}=0.08$ ) and Age (standardized $\beta=0.06, \mathrm{p}=0.69$ ).

\section{DISCUSSION}

Our current results show that patterns of functional activation magnitude regarded as the hallmark of CRUNCH (under- and over-activation during lower and higher difficulty task conditions, respectively), and typically observed in cross-sectional comparisons between older and younger adults, discriminate between older adults with higher and lower WMC. Functional modulation range during the N-Back was not only indicative of in-scanner NBack performance, but moreover, individual differences in WMC as measured by a set of out-of-scanner tasks that are a standard of WMC assessment in psychometric research (Conway et al., 2005; Redick et al., 2012). Importantly, a significant relationship between range of functional modulation during the N-Back task and WMC was observed in the absence of significant relationships between N-Back and complex span task performance. We interpret these findings as suggesting that dynamic range of functional modulation may indicate WMC limitations that may not be reflected in task performance.

In addition to our current results, a growing body of evidence suggests that the ability to modulate functional activation in accordance with manipulations of task difficulty is a potentially important indicator of neurocognitive functioning in aging (Cappell et al., 2010; Hedden, Van Dijk, et al., 2012; Kaup et al., 2014; Kennedy et al., 2015; Mattay et al., 2006; Nagel et al., 2009, 2011; Park, Polk, Hebrank, \& Jenkins, 2010; Persson, Lustig, Nelson, \& Reuter-Lorenz, 2007; Rieck, Rodrigue, Boylan, \& Kennedy, 2017; Sambataro et al., 2010; Schneider-Garces et al., 2010). Importantly, these changes are not limited to "task-positive" brain networks such as the frontoparietal network investigated here, but also networks that show patterns of task-related deactivation (e.g., regions of the default-mode network; Brown, Hakun, Zhu, Johnson, \& Gold, 2015; Park et al., 2010; Persson et al., 2007; Sambataro et al., 2010). Recent evidence suggests that modulation of task-positive and task-deactivated networks may be dynamically coupled (G. R. Turner \& Spreng, 2015). Consistent with our current results, a recent study by Rieck and colleagues (2017) showed that modulatory coupling between task activated and deactivated networks is associated with individual 
differences in fluid intelligence (Rieck et al., 2017), which is highly associated with WMC (Conway et al., 2003; Kane et al., 2004; Kyllonen \& Christal, 1990; Unsworth et al., 2014). Together with our current results, these findings suggest that higher-order cognitive abilities such as WMC and fluid intelligence may be altered by age-related changes in the neurocognitive resources that underlie domain-general WM processes.

We observed that the slope of functional modulation across levels of the N-Back accounted for $9-11 \%$ of the variance in WMC (before/after controlling for age and mean activation magnitude). Importantly, this relationship was observed in the absence of significant relationships between performance on the N-Back and complex span tasks. However, it is important to note that the low correlation values between the N-Back and WMC estimates observed here are not anomalous, as the N-Back and WMC were, similarly, only weakly (2-5\% shared variance) or uncorrelated in previous studies (Kane et al., 2007; Redick \& Lindsey, 2013; Roberts \& Gibson, 2002). Several explanations have been proposed to account for the lack of correlation between tasks such as differences in decision-related processes (familiarity- vs recollection-based decisions), as is described in more detail elsewhere (see Jaeggi, Buschkuehl, Perrig, \& Meier, 2010). We can not rule out participant use of verbal strategies during the visual N-Back task conditions (e.g. naming the emotional expressions), which may have influenced the performance correlations observed here. Importantly, however, the observation that activation patterns during N-Back performance are predictive of WMC is consistent with the proposal that the tasks rely on common underlying processes (Schmiedek, Hildebrandt, Lövdén, Lindenberger, \& Wilhelm, 2009).

The N-Back task is frequently utilized in applied cognitive neuroscience research due to its adaptability to the fMRI scanner environment, the ability to parametrically manipulate task demand by increasing the working memory load (increasing the "N"), and the surface validity of the relevant task-induced cognitive operations (e.g. updating, maintenance, resistance to proactive interference; Jaeggi et al., 2010). Meta-analysis of fMRI activation patterns during N-Back performance show that N-Back performance engages a similar set of brain regions distributed throughout dorsal and ventral frontoparietal cortices as observed here (Burgess, Gray, Conway, \& Braver, 2011; Owen et al., 2005; Rottschy et al., 2012). In studies comparing younger and older adults, a clear pattern has emerged indicating that while frontoparietal activation magnitude scales parametrically with increase in the N-Back judgment in younger adults, older adults exhibit higher activation at lower levels of the $\mathrm{N}$ Back and lower overall functional modulation (Burzynska et al., 2013; Nagel et al., 2011).

In our sample, decreases in range of modulation were observed over less than two decades in age range. Similar to a recent study by Nagel and colleagues (2011) we observed significant relationships between functional modulation and performance on the N-Back task (in the form of sub-group differences in accuracy between individuals with low and high slopes). However, the relationships observed in our primary analyses were between modulation range over all levels of the task and performance during COMPARE, 1-Back, and 2-Back conditions, where Nagel and colleagues observed a significant correlation between 3-Back performance and modulation from the 1-Back to 2-Back conditions (Nagel et al., 2011). A re-analysis of our own data replicated this relationship $(r=0.32, p=0.02)$ such that 
individuals who exhibited greater increases from the 1-Back to the 2-Back conditions exhibited higher accuracy during the 3-Back condition.

The specific cognitive mechanisms that drive individual variability in WMC-limitations remain widely debated, and much of the debate centers around whether capacity is limited more or less by processing or representational (i.e. storage) mechanisms. A common feature shared among domain-general descriptions of WMC is that individual differences are more likely to reflect differences in the ability to control WM processing and prioritization than the ability to passively store a certain quantity of information (Chun, 2011; Cowan, 1999, 2005; Engle, 2002; Kane \& Engle, 2003; Oberauer et al., 2012; Unsworth et al., 2014). These controlled processing abilities include the ability to control and divide attention (Chun, 2011; Engle, 2002; Kane \& Engle, 2003), the ability to actively remove irrelevant information (Oberauer et al., 2012), and the ability to efficiently retrieve from secondary memory (i.e. long-term memory or the periphery of the focus of attention in working memory; Mogle, Lovett, Stawski, \& Sliwinski, 2008; Unsworth et al., 2014). Similarly, aging is associated with greater declines in controlled WM processing than passive shortterm memory maintenance (Bopp \& Verhaeghen, 2005; Braver \& West, 2008; Hasher, Lustig, \& Zacks, 2007; Park et al., 2002; Park \& Hedden, 2001; although see Hale et al., 2011). Along with previous findings (Cappell et al., 2010; Schneider-Garces et al., 2010), our current study suggests that there may be neurocognitive contributions to WMClimitations related to the ability to recruit functional regions distributed throughout frontoparietal cortices. These findings are consistent with recent neurocognitive theories of distributed WM and fit well with the presumed role of a frontoparietal brain network in controlled cognition (Christophel, Klink, Spitzer, Roelfsema, \& Haynes, 2017; Cole, Repovš, \& Anticevic, 2014; Hazy, Frank, \& O’Reilly, 2007; Jurado \& Rosselli, 2007; Niendam et al., 2012; G. R. Turner \& Spreng, 2012; Vandierendonck, 2016; Vincent, Kahn, Snyder, Raichle, \& Buckner, 2008; Zanto \& Gazzaley, 2013)

If range of functional modulation indeed reflects the ability to engage in controlled cognitive processing, then the consequences of this restricted range should be evident in other tasks and operations that rely on cognitive control. For example, we would expect individuals with a more restricted range of modulation to perform more poorly on dual tasks, divided/ selective attention tasks, task switching, and perhaps also daily activities such as driving or maintaining prospective memory performance under conditions of distraction (see also Braver \& West, 2008). Here we examined a domain-general measure of N-Back performance but we propose that a multi-task domain approach (e.g. diversity-unity approach; Miyake et al., 2000; Miyake \& Friedman, 2012) would serve to benefit future work in this area.

Age and WMC were each associated with frontoparietal functional modulation, but WMC and Age were not interrelated. WMC declines with age (Hale et al., 2011; Mccabe, Roediger III, Mcdaniel, Balota, Hambrick, 2010; Park et al., 2002), and despite observing a wide range in WMC and functional modulation we did not observe a significant relationship between age and WMC. We expect that this is primarily due to the limited age range present in our sample. However, it is important to note that a lack of correlation between WMC and Age confirms that the relationship between functional modulation and WMC was not driven 
purely by age-related change in each variable (see also multiple regression results). Future studies would benefit from a broader age range, longitudinal follow-up, and lifespan approaches to the questions investigated here. In addition to a limited age range among older adults, we did not include a younger adult sample in our study. The focus of the current study on older adults was motivated by an extensive literature documenting patterns of agerelated functional over-recruitment and recent evidence examining age-related changes in functional modulation. It is possible, however, that the modulation-WMC relationship may be age-invariant and therefore should be examined in future work. We note that age was negatively associated with modulation range in our sample, suggesting that this factor is sensitive to aging, but we cannot rule out modulation range as a general marker of cognitive ability throughout the adult lifespan (see Rieck et al., 2017). Lastly, a variety of age-related neurophysiological factors beyond chronological age may underlie individual differences in the ability to modulate functional modulation including changes in gray and white matter, neurovascular coupling mechanisms, and neurodegenerative pathology (Brown et al., 2015; Buckner, 2005; Burzynska et al., 2013; Drzezga et al., 2011; Girouard \& Iadecola, 2005; Hakun, Zhu, Brown, Johnson, \& Gold, 2015; Hedden, Mormino, et al., 2012; Hedden, Van Dijk, et al., 2012). Multi-modal imaging efforts could further our understanding of these neurocognitive relationships in future work.

\section{CONCLUSIONS}

Our current findings show that the dynamic range of functional modulation throughout a frontoparietal network of brain regions discriminates between older adults with higher and lower WMC. These findings extend previous cross-sectional evidence suggesting that brain functional modulation is a potentially important indicator of neurocognitive functioning in older adults. Future work should elucidate the specific mechanisms that underlie reduction of functional modulation in aging and examine the degree to which modulation is a determinant of other areas of cognitive ability and daily functioning.

\section{Acknowledgments}

This study was supported by the National Institute on Aging of the National Institutes of Health under award number KL2 UL1TR000116. We thank Eric Forman for his help collecting data and coordinating the study. We also thank Avery Rizio for her helpful comments on an earlier draft of the manuscript. The content is solely the responsibility of the authors and does not necessarily represent the official views of the granting agencies.

\section{References}

Alvarez GA, Cavanagh P. The Capacity of Visual Short-Term Memory is Set Both by Visual Information Load and by Number of Objects. Psychological Science. 2004; 15(2):106-111. http:// doi.org/10.1111/j.0963-7214.2004.01502006.x. [PubMed: 14738517]

Andersson J, Jenkinson M, Smith SM. Non-linear registration aka Spatial normalisation FMRIB Technial Report TR07JA2. 2007

Baddeley AD. Working memory: looking back and looking forward. Nature Reviews Neuroscience. 2003; 4(10):829-839. http://doi.org/10.1038/nrn1201. [PubMed: 14523382]

Baddeley AD, Hitch G. Working Memory. Psychology of Learning and Motivation. 1974; 8:47-89. http://doi.org/10.1016/S0079-7421(08)60452-1. 
Barrouillet P, Bernardin S, Camos V. Time Constraints and Resource Sharing in Adults' Working Memory Spans. Journal of Experimental Psychology: General. 2004; 133(1):83-100. http://doi.org/ 10.1037/0096-3445.133.1.83. [PubMed: 14979753]

Bays PM, Catalao RFG, Husain M, A AG, P C, E A, J LS. The precision of visual working memory is set by allocation of a shared resource. Journal of Vision. 2009; 9(10):7-7. A., A. G., P., C., E., A., ... J., L. S. http://doi.org/10.1167/9.10.7.

Bopp KL, Verhaeghen P. Aging and Verbal Memory Span: A Meta-Analysis. The Journals of Gerontology Series B: Psychological Sciences and Social Sciences. 2005; 60(5):P223-P233. http:// doi.org/10.1093/geronb/60.5.P223.

Braver, TS., West, R. Working memory, executive control, and aging. Psychology Press; 2008.

Brown CA, Hakun JG, Zhu Z, Johnson NF, Gold BT. White matter microstructure contributes to agerelated declines in task-induced deactivation of the default mode network. Frontiers in Aging Neuroscience. 2015; 7:194. http://doi.org/10.3389/fnagi.2015.00194. [PubMed: 26500549]

Buckner RL. Molecular, Structural, and Functional Characterization of Alzheimer's Disease: Evidence for a Relationship between Default Activity, Amyloid, and Memory. Journal of Neuroscience. 2005; 25(34):7709-7717. http://doi.org/10.1523/JNEUROSCI.2177-05.2005. [PubMed: $16120771]$

Burgess GC, Gray JR, Conway ARA, Braver TS. Neural mechanisms of interference control underlie the relationship between fluid intelligence and working memory span. Journal of Experimental Psychology: General. 2011; 140(4):674-692. http://doi.org/10.1037/a0024695. [PubMed: 21787103]

Burzynska A, Garrett DD, Preuschhof C, Nagel IE, Li SC, Backman L, Lindenberger U. A Scaffold for Efficiency in the Human Brain. Journal of Neuroscience. 2013; 33(43):17150-17159. http:// doi.org/Doi10.1523/Jneurosci.1426-13.2013. [PubMed: 24155318]

Cabeza R, Anderson ND, Locantore JK, McIntosh AR. Aging Gracefully: Compensatory Brain Activity in High-Performing Older Adults. NeuroImage. 2002; 17(3):1394-1402. http://doi.org/ 10.1006/nimg.2002.1280. [PubMed: 12414279]

Cabeza, R., Dennis, NA. Frontal lobes and aging: Deterioration and compensation. In: K. R. T Stuss DT. , editor. Principles of Frontal Lobe Function. 2nd. New York: Oxford University Press; 2012. p. 628-652.

Cappell KA, Gmeindl L, Reuter-Lorenz PA. Age differences in prefontal recruitment during verbal working memory maintenance depend on memory load. Cortex. 2010; 46(4):462-473. [PubMed: 20097332]

Christophel TB, Klink PC, Spitzer B, Roelfsema PR, Haynes JD. The Distributed Nature of Working Memory. Trends in Cognitive Sciences. 2017; 21(2):111-124. http://doi.org/10.1016/j.tics. 2016.12.007. [PubMed: 28063661]

Chun MM. Visual working memory as visual attention sustained internally over time. Neuropsychologia. 2011; 49(6):1407-1409. http://doi.org/10.1016/j.neuropsychologia. 2011.01.029. [PubMed: 21295047]

Colcombe SJ, Kramer AF, Erickson KI, Scalf PE. The implications of cortical recruitment and brain morphology for individual differences in inhibitory function in aging humans. Psychology and Aging. 2005; 20(3):363. [PubMed: 16248697]

Cole MW, Repovš G, Anticevic A. The Frontoparietal Control System. The Neuroscientist. 2014; 20(6):652-664. http://doi.org/10.1177/1073858414525995. [PubMed: 24622818]

Conway ARA, Kane MJ, Bunting MF, Hambrick DZ, Wilhelm O, Engle RW. Working memory span tasks: A methodological review and user's guide. Psychonomic Bulletin \& Review. 2005; 12(5): 769-786. http://doi.org/10.3758/BF03196772. [PubMed: 16523997]

Conway ARA, Kane MJ, Engle RW. Working memory capacity and its relation to general intelligence. Trends in Cognitive Sciences. 2003; 7(12):547-552. http://doi.org/10.1016/j.tics.2003.10.005. [PubMed: 14643371]

Cowan, N. An Embedded-Processes Model of Working Memory. In: Miyake, A., Shah, P., editors. Models of Working Memory. Cambridge: Cambridge University Press; 1999. p. 62-101.http:// doi.org/10.1017/CBO9781139174909.006 
Cowan, N. working memory capacity. Abingdon, UK: Taylor \& Francis; 2005. http://doi.org/ $10.4324 / 9780203342398$

Cowan N. The Magical Mystery Four. Current Directions in Psychological Science. 2010; 19(1):5157. http://doi.org/10.1177/0963721409359277. [PubMed: 20445769]

Dolcos F, Rice HJ, Cabeza R. Hemispheric asymmetry and aging: right hemisphere decline or asymmetry reduction. Neuroscience \& Biobehavioral Reviews. 2002; 26(7):819-825. http:// doi.org/10.1016/S0149-7634(02)00068-4. [PubMed: 12470693]

Drag LL, Bieliauskas LA. Contemporary Review 2009: Cognitive Aging. Journal of Geriatric Psychiatry and Neurology. 2010; 23(2):75-93. http://doi.org/Doi10.1177/0891988709358590. [PubMed: 20101069]

Drzezga A, Becker JA, Van Dijk KRA, Sreenivasan A, Talukdar T, Sullivan C, Sperling RA. Neuronal dysfunction and disconnection of cortical hubs in non-demented subjects with elevated amyloid burden. Brain. 2011; 134(6):1635-1646. http://doi.org/10.1093/brain/awr066. [PubMed: 21490054]

Engle RW. Working Memory Capacity as Executive Attention. Current Directions in Psychological Science. 2002; 11(1):19-23. http://doi.org/10.1111/1467-8721.00160.

Girouard H, Iadecola C. Neurovascular coupling in the normal brain and in hypertension, stroke, and Alzheimer disease. Journal of Applied Physiology. 2005; 100(1)

Grady CL. BRAIN AGEING The cognitive neuroscience of ageing. Nature Reviews Neuroscience. 2012; 13(7):491-505. http://doi.org/Doi10.1038/Nrn3256. [PubMed: 22714020]

Hakun JG, Zhu Z, Brown CA, Johnson NF, Gold BT. Longitudinal alterations to brain function, structure, and cognitive performance in healthy older adults: A fMRI-DTI study. Neuropsychologia. 2015; 71:225-235. http://doi.org/10.1016/j.neuropsychologia.2015.04.008. [PubMed: 25862416]

Hale S, Rose NS, Myerson J, Strube MJ, Sommers M, Tye-Murray N, Spehar B. The structure of working memory abilities across the adult life span. Psychology and Aging. 2011; 26(1):92-110. http://doi.org/10.1037/a0021483. [PubMed: 21299306]

Hasher L, Lustig C, Zacks RT. Inhibitory mechanisms and the control of attention. Variation in Working Memory. 2007:227-249.

Hasher L, Zacks RT. Working memory, comprehension, and aging: A review and a new view. Psychology of Learning and Motivation. 1988; 22:193-225.

Hazy TE, Frank MJ, O'Reilly RC. Towards an executive without a homunculus: computational models of the prefrontal cortex/basal ganglia system. Philosophical Transactions of the Royal Society of London B: Biological Sciences. 2007; 362(1485)

Hedden T, Mormino EC, Amariglio RE, Younger AP, Schultz AP, Becker JA, Rentz DM. Cognitive Profile of Amyloid Burden and White Matter Hyperintensities in Cognitively Normal Older Adults. Journal of Neuroscience. 2012; 32(46)

Hedden, T., Van Dijk, KRA., Shire, EH., Sperling, RA., Johnson, KA., Buckner, RL. Cerebral Cortex. Vol. 22. New York, N.Y.: 2012. Failure to modulate attentional control in advanced aging linked to white matter pathology; p. 1038-51.1991http://doi.org/10.1093/cercor/bhr172

Jaeggi SM, Buschkuehl M, Perrig WJ, Meier B. The concurrent validity of the N -back task as a working memory measure. Memory. 2010; 18(4):394-412. http://doi.org/ 10.1080/09658211003702171. [PubMed: 20408039]

Jenkinson M, Beckmann CF, Behrens TEJ, Woolrich MW, Smith SM. FSL. NeuroImage. 2012; 62(2): 782-790. http://doi.org/10.1016/j.neuroimage.2011.09.015. [PubMed: 21979382]

Jurado MB, Rosselli M. The Elusive Nature of Executive Functions: A Review of our Current Understanding. Neuropsychology Review. 2007; 17(3):213-233. http://doi.org/10.1007/ s11065-007-9040-z. [PubMed: 17786559]

Kane MJ, Conway ARA, Miura TK, Colflesh GJH. Working memory, attention control, and the n-back task: A question of construct validity. Journal of Experimental Psychology: Learning, Memory, and Cognition. 2007; 33(3):615-622. http://doi.org/10.1037/0278-7393.33.3.615.

Kane MJ, Engle RW. Working-memory capacity and the control of attention: The contributions of goal neglect, response competition, and task set to Stroop interference. Journal of Experimental 
Psychology: General. 2003; 132(1):47-70. http://doi.org/10.1037/0096-3445.132.1.47. [PubMed: 12656297]

Kane MJ, Hambrick DZ, Tuholski SW, Wilhelm O, Payne TW, Engle RW. The Generality of Working Memory Capacity: A Latent-Variable Approach to Verbal and Visuospatial Memory Span and Reasoning. Journal of Experimental Psychology: General. 2004; 133(2):189-217. http://doi.org/ 10.1037/0096-3445.133.2.189. [PubMed: 15149250]

Kaup AR, Drummond SPA, Eyler LT. Brain functional correlates of working memory: reduced loadmodulated activation and deactivation in aging without hyperactivation or functional reorganization. Journal of the International Neuropsychological Society: JINS. 2014; 20(9):94550. http://doi.org/10.1017/S1355617714000824. [PubMed: 25263349]

Kennedy KM, Partridge T, Raz N. Age-Related Differences in Acquisition of Perceptual-Motor Skills: Working Memory as a Mediator. Aging, Neuropsychology, and Cognition. 2008; 15(2):165-183. http://doi.org/10.1080/13825580601186650.

Kennedy KM, Rodrigue KM, Bischof GN, Hebrank AC, Reuter-Lorenz PA, Park DC. Age trajectories of functional activation under conditions of low and high processing demands: an adult lifespan fMRI study of the aging brain. NeuroImage. 2015; 104:21-34. http://doi.org/10.1016/ j.neuroimage.2014.09.056. [PubMed: 25284304]

Kyllonen PC, Christal RE. Reasoning ability is (little more than) working-memory capacity?! Intelligence. 1990; 14(4):389-433. http://doi.org/10.1016/S0160-2896(05)80012-1.

Linden DEJ, Bittner RA, Muckli L, Waltz JA, Kriegeskorte N, Goebel R, Munk MHJ. Cortical capacity constraints for visual working memory: Dissociation of fMRI load effects in a frontoparietal network. NeuroImage. 2003; 20(3):1518-1530. http://doi.org/10.1016/j.neuroimage. 2003.07.021. [PubMed: 14642464]

Luck SJ, Vogel EK. Visual working memory capacity: from psychophysics and neurobiology to individual differences. Trends in Cognitive Sciences. 2013; 17(8):391-400. http://doi.org/10.1016/ j.tics.2013.06.006. [PubMed: 23850263]

Lustig C, Hasher L, Zacks RT. Inhibitory deficit theory: Recent developments in a "new view". Inhibition in Cognition. 2007:145-162.

Mattay VS, Fera F, Tessitore A, Hariri AR, Berman KF, Das S, Weinberger DR. Neurophysiological correlates of age-related changes in working memory capacity. Neuroscience Letters. 2006; 392(1):32-37. http://doi.org/10.1016/j.neulet.2005.09.025. [PubMed: 16213083]

Mccabe DP, Roediger Henry L III, Mcdaniel MA, Balota DA, Hambrick DZ. The Relationship Between Working Memory Capacity and Executive Functioning: Evidence for a Common Executive Attention Construct. Neuropsychology. 2010; 24(2):222-243. http://doi.org/10.1037/ a0017619. [PubMed: 20230116]

McCollough AW, Machizawa MG, Vogel EK. Electrophysiological Measures of Maintaining Representations in Visual Working Memory. Cortex. 2007; 43(1):77-94. http://doi.org/10.1016/ S0010-9452(08)70447-7. [PubMed: 17334209]

Miller GA. The magical number seven plus or minus two: some limits on our capacity for processing information. Psychological Review. 1956; 63(2):81-97. [PubMed: 13310704]

Miyake A, Friedman NP. The Nature and Organization of Individual Differences in Executive Functions: Four General Conclusions. Current Directions in Psychological Science. 2012; 21(1):814. http://doi.org/10.1177/0963721411429458. [PubMed: 22773897]

Miyake A, Friedman NP, Emerson MJ, Witzki AH, Howerter A, Wager TD. The Unity and Diversity of Executive Functions and Their Contributions to Complex "Frontal Lobe" Tasks: A Latent Variable Analysis. Cognitive Psychology. 2000; 41(1):49-100. http://doi.org/10.1006/cogp. 1999.0734. [PubMed: 10945922]

Mogle JA, Lovett BJ, Stawski RS, Sliwinski MJ. What's So Special About Working Memory? An Examination of the Relationships Among Working Memory, Secondary Memory, and Fluid Intelligence. Psychological Science. 2008; 19(11):1071-1077. http://doi.org/10.1111/j. 1467-9280.2008.02202.x. [PubMed: 19076475]

Nagel IE, Preuschhof C, Li SC, Nyberg L, Bäckman L, Lindenberger U, Heekeren HR. Performance level modulates adult age differences in brain activation during spatial working memory. 
Proceedings of the National Academy of Sciences of the United States of America. 2009; 106(52): 22552-7. http://doi.org/10.1073/pnas.0908238106. [PubMed: 20018709]

Nagel IE, Preuschhof C, Li SC, Nyberg L, Bäckman L, Lindenberger U, Heekeren HR. Load Modulation of BOLD Response and Connectivity Predicts Working Memory Performance in Younger and Older Adults. Journal of Cognitive Neuroscience. 2011; 23(8):2030-2045. http:// doi.org/10.1162/jocn.2010.21560. [PubMed: 20828302]

Nee, DE., Brown, JW., Askren, MK., Berman, MG., Demiralp, E., Krawitz, A., Jonides, J. Cerebral Cortex. Vol. 23. New York, N.Y.: 2013. A meta-analysis of executive components of working memory; p. 264-82.1991http://doi.org/10.1093/cercor/bhs007

Niendam TA, Laird AR, Ray KL, Dean YM, Glahn DC, Carter CS. Meta-analytic evidence for a superordinate cognitive control network subserving diverse executive functions. Cogn Affect Behav Neurosci. 2012; 12(2):241-268. http://doi.org/10.3758/s13415-011-0083-5. [PubMed: 22282036]

Oberauer K, Lewandowsky S, Farrell S, Jarrold C, Greaves M. Modeling working memory: an interference model of complex span. Psychonomic Bulletin \& Review. 2012; 19(5):779-819. http://doi.org/10.3758/s13423-012-0272-4. [PubMed: 22715024]

Owen AM, McMillan KM, Laird AR, Bullmore E. N-back working memory paradigm: A metaanalysis of normative functional neuroimaging studies. Human Brain Mapping. 2005; 25(1):4659. http://doi.org/10.1002/hbm.20131. [PubMed: 15846822]

Park DC, Hedden T. Working memory and aging. Perspectives on human memory and cognitive aging: Essays in honour of Fergus Craik. 2001:148-160.

Park DC, Lautenschlager G, Hedden T, Davidson NS, Smith AD, Smith PK. Models of visuospatial and verbal memory across the adult life span. Psychology and Aging. 2002; 17(2):299-320. http:// doi.org/10.1037/0882-7974.17.2.299. [PubMed: 12061414]

Park DC, Polk TA, Hebrank AC, Jenkins L. Age differences in default mode activity on easy and difficult spatial judgment tasks. Frontiers in Human Neuroscience. 2010; 3:75. http://doi.org/ 10.3389/neuro.09.075.2009. [PubMed: 20126437]

Park DC, Smith AD, Lautenschlager G, Earles JLD, et al. Zwahr M, Gaines CL. Mediators of longterm memory performance across the life span. Psychology and Aging. 1996; 11(4):621-637. http://doi.org/10.1037/0882-7974.11.4.621. [PubMed: 9000294]

Persson J, Lustig C, Nelson JK, Reuter-Lorenz PA. Age Differences in Deactivation: A Link to Cognitive Control? Journal of Cognitive Neuroscience. 2007; 19(6):1021-1032. http://doi.org/ 10.1162/jocn.2007.19.6.1021. [PubMed: 17536972]

Redick TS, Broadway JM, Meier ME, Kuriakose PS, Unsworth N, Kane MJ, Engle RW. Measuring Working Memory Capacity With Automated Complex Span Tasks. WMC Tasks European Journalof Psychological Assessment. 2012; 28(3):164-171. http://doi.org/10.1027/1015-5759/ a000123.

Redick TS, Lindsey DRB. Complex span and n-back measures of working memory: A meta-analysis. Psychonomic Bulletin \& Review. 2013; 20(6):1102-1113. http://doi.org/10.3758/ s13423-013-0453-9. [PubMed: 23733330]

Reuter-Lorenz PA, Cappell KA. Neurocognitive aging and the compensation hypothesis. Current Directions in Psychological Science. 2008; 17(3):177-182. http://doi.org/DOI10.1111/j. 1467-8721.2008.00570.x.

Reuter-Lorenz PA, Park DC. Human neuroscience and the aging mind: a new look at old problems. J Gerontol B Psychol Sci Soc Sci. 2010; 65(4):405-415. http://doi.org/10.1093/geronb/gbq035. [PubMed: 20478901]

Rieck JR, Rodrigue KM, Boylan MA, Kennedy KM. Age-related reduction of BOLD modulation to cognitive difficulty predicts poorer task accuracy and poorer fluid reasoning ability. NeuroImage. 2017; 147:262-271. http://doi.org/10.1016/j.neuroimage.2016.12.022. [PubMed: 27979789]

Roberts R, Gibson E. Individual differences in sentence memory. Journal of Psycholinguistic Research. 2002; 31(6):573-98. [PubMed: 12599915]

Rottschy C, Langner R, Dogan I, Reetz K, Laird AR, Schulz JB, Eickhoff SB. Modelling neural correlates of working memory: A coordinate-based meta-analysis. NeuroImage. 2012; 60(1):830846. http://doi.org/10.1016/j.neuroimage.2011.11.050. [PubMed: 22178808] 
Salthouse TA. Working memory as a processing resource in cognitive aging. Developmental Review. 1990; 10(1):101-124. http://doi.org/10.1016/0273-2297(90)90006-P.

Sambataro F, Murty VP, Callicott JH, Tan HY, Das S, Weinberger DR, Mattay VS. Age-related alterations in default mode network: impact on working memory performance. Neurobiology of Aging. 2010; 31(5):839-52. http://doi.org/10.1016/j.neurobiolaging.2008.05.022. [PubMed: 18674847]

Schmiedek F, Hildebrandt A, Lövdén M, Lindenberger U, Wilhelm O. Complex span versus updating tasks of working memory: the gap is not that deep. Journal of Experimental Psychology. Learning, Memory, and Cognition. 2009; 35(4):1089-1096. http://doi.org/10.1037/a0015730.

Schneider-Garces NJ, Gordon BA, Brumback-Peltz CR, Shin E, Lee Y, Sutton BP, Fabiani M. Span, CRUNCH, and beyond: working memory capacity and the aging brain. Journal of Cognitive Neuroscience. 2010; 22(4):655-69. http://doi.org/10.1162/jocn.2009.21230. [PubMed: 19320550]

Song JH, Jiang Y. Visual working memory for simple and complex features: An fMRI study. NeuroImage. 2006; 30

Todd JJ, Marois R. Capacity limit of visual short-term memory in human posterior parietal cortex. Nature. 2004; 428(6984):751-754. http://doi.org/10.1038/nature02466. [PubMed: 15085133]

Todd JJ, Marois R. Posterior parietal cortex activity predicts individual differences in visual short-term memory capacity. Cognitive, Affective, \& Behavioral Neuroscience. 2005; 5(2):144-155. http:// doi.org/10.3758/CABN.5.2.144.

Turner GR, Spreng RN. Executive functions and neurocognitive aging: dissociable patterns of brain activity. Neurobiology of Aging. 2012; 33(4) http://doi.org/Doi10.1016/J.Neurobiolaging. 2011.06.005.

Turner GR, Spreng RN. Prefrontal Engagement and Reduced Default Network Suppression Co-occur and Are Dynamically Coupled in Older Adults: The Default-Executive Coupling Hypothesis of Aging. Journal of Cognitive Neuroscience. 2015; 27(12):2462-2476. http://doi.org/10.1162/ jocn_a_00869. [PubMed: 26351864]

Turner ML, Engle RW. Working Memory Capacity. Proceedings of the Human Factors and Ergonomics Society Annual Meeting. 1986; 30(13):1273-1277. http://doi.org/ $10.1177 / 154193128603001307$.

Unsworth N, Fukuda K, Awh E, Vogel EK. Working memory and fluid intelligence: Capacity, attention control, and secondary memory retrieval. Cognitive Psychology. 2014; 71:1-26. http://doi.org/ 10.1016/j.cogpsych.2014.01.003. [PubMed: 24531497]

Vandierendonck A. A Working Memory System With Distributed Executive Control. Perspectives on Psychological Science. 2016; 11(1):74-100. http://doi.org/10.1177/1745691615596790. [PubMed: 26817727]

Vincent JL, Kahn I, Snyder AZ, Raichle ME, Buckner RL. Evidence for a Frontoparietal Control System Revealed by Intrinsic Functional Connectivity. Journal of Neurophysiology. 2008; 100(6): 3328-3342. http://doi.org/10.1152/jn.90355.2008. [PubMed: 18799601]

Vogel EK, Machizawa MG. Neural activity predicts individual differences in visual working memory capacity. Nature. 2004; 428(6984):748-751. http://doi.org/10.1038/nature02447. [PubMed: 15085132]

Wager TD, Smith EE. Neuroimaging studies of working memory. Cognitive, Affective, \& Behavioral Neuroscience. 2003; 3(4):255-274. http://doi.org/10.3758/CABN.3.4.255.

$\mathrm{Xu}$ Y, Chun MM. Dissociable neural mechanisms supporting visual short-term memory for objects. Nature. 2006; 440(7080):91-95. http://doi.org/10.1038/nature04262. [PubMed: 16382240]

Zanto TP, Gazzaley A. Fronto-parietal network: flexible hub of cognitive control. Trends in Cognitive Sciences. 2013; 17(12):602-603. http://doi.org/10.1016/j.tics.2013.09.011. [PubMed: 24129332] 


\section{Highlights}

- $\quad$ Older adults with greater modulation range exhibited better in-scanner performance

- Frontoparietal functional modulation predicted psychometric working memory capacity

- $\quad$ Modulation range decreased with age

- Older adults with lower modulation range showed "CRUNCH"-like pattern of activation 

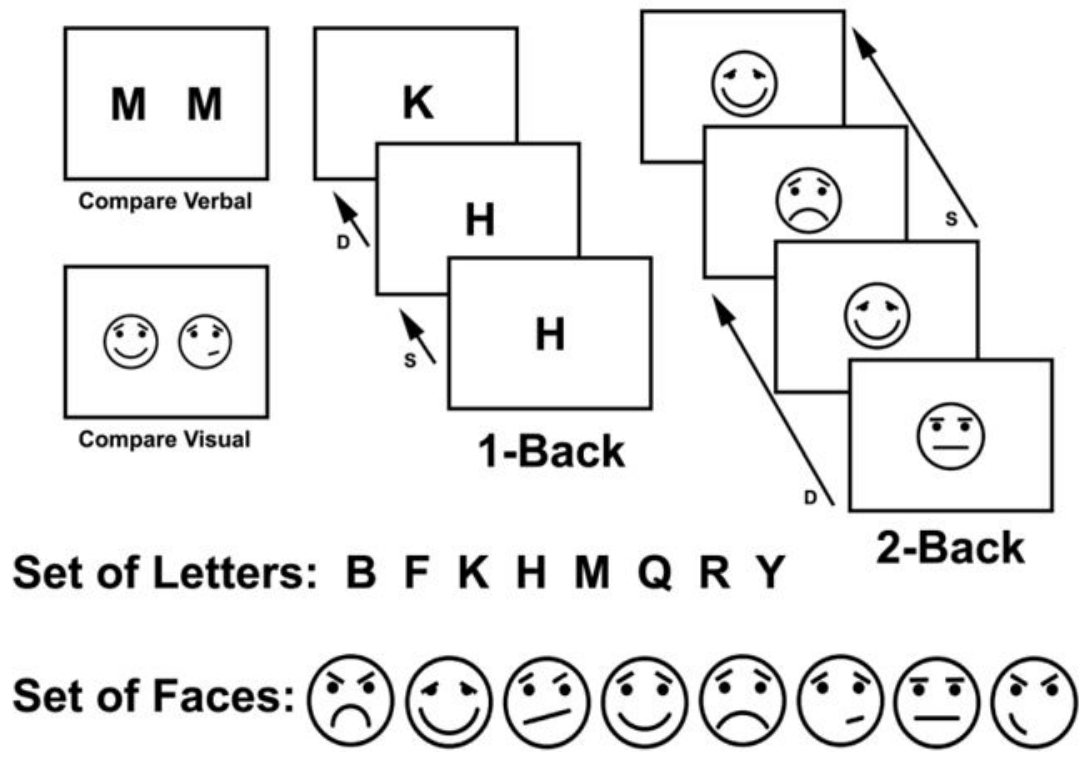

Figure 1. N-Back Task Design

(TOP) Example verbal and visual stimulus displays for the Compare, 1-Back, and 2-Back task conditions. 3-Back condition is not displayed. (BOTTOM) Complete set of letter and face stimuli. $\mathrm{S}=$ "same", $\mathrm{D}=$ Different". 
(A)

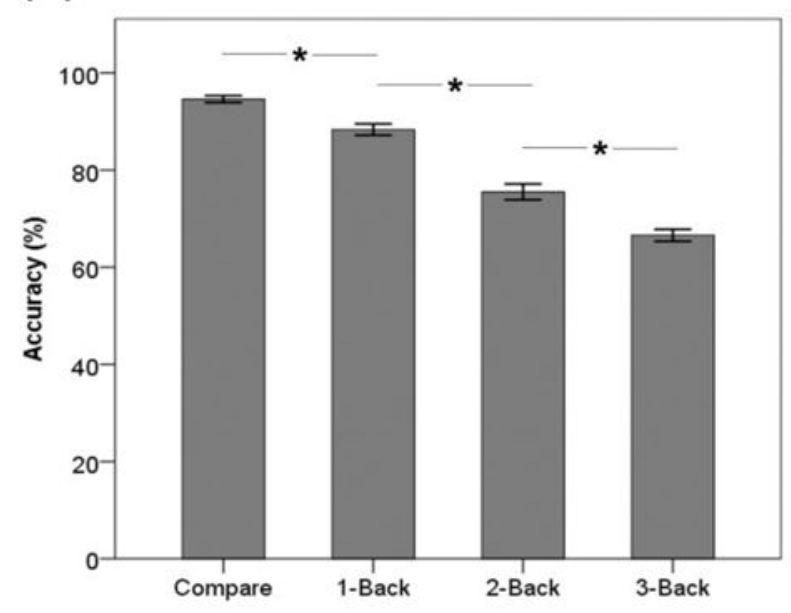

(B)

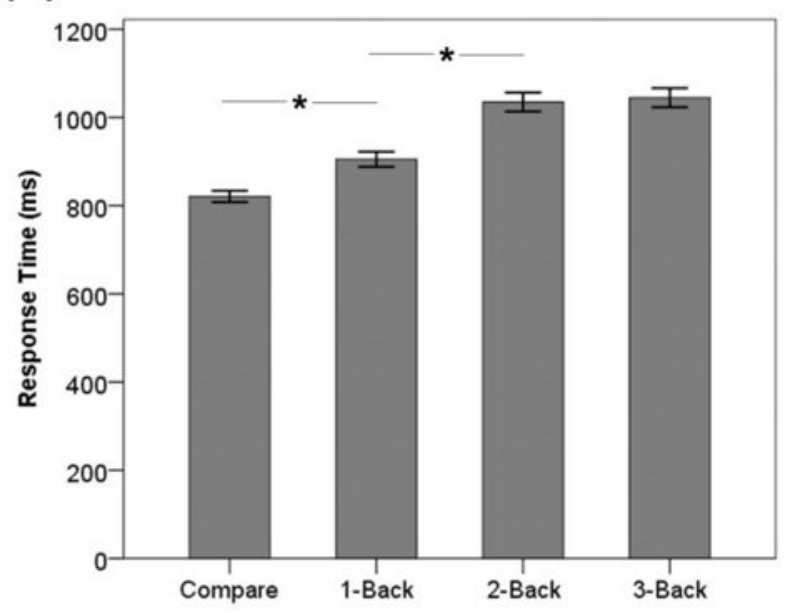

Figure 2. Accuracy and Response Time

(A) A significant reduction in accuracy was observed between each level of the task (B) A significant increase in RT was observed between the Compare and 1-Back conditions as well as the 1-Back and 2-Back conditions. RT did not increase between the 2-Back and 3-Back conditions. 

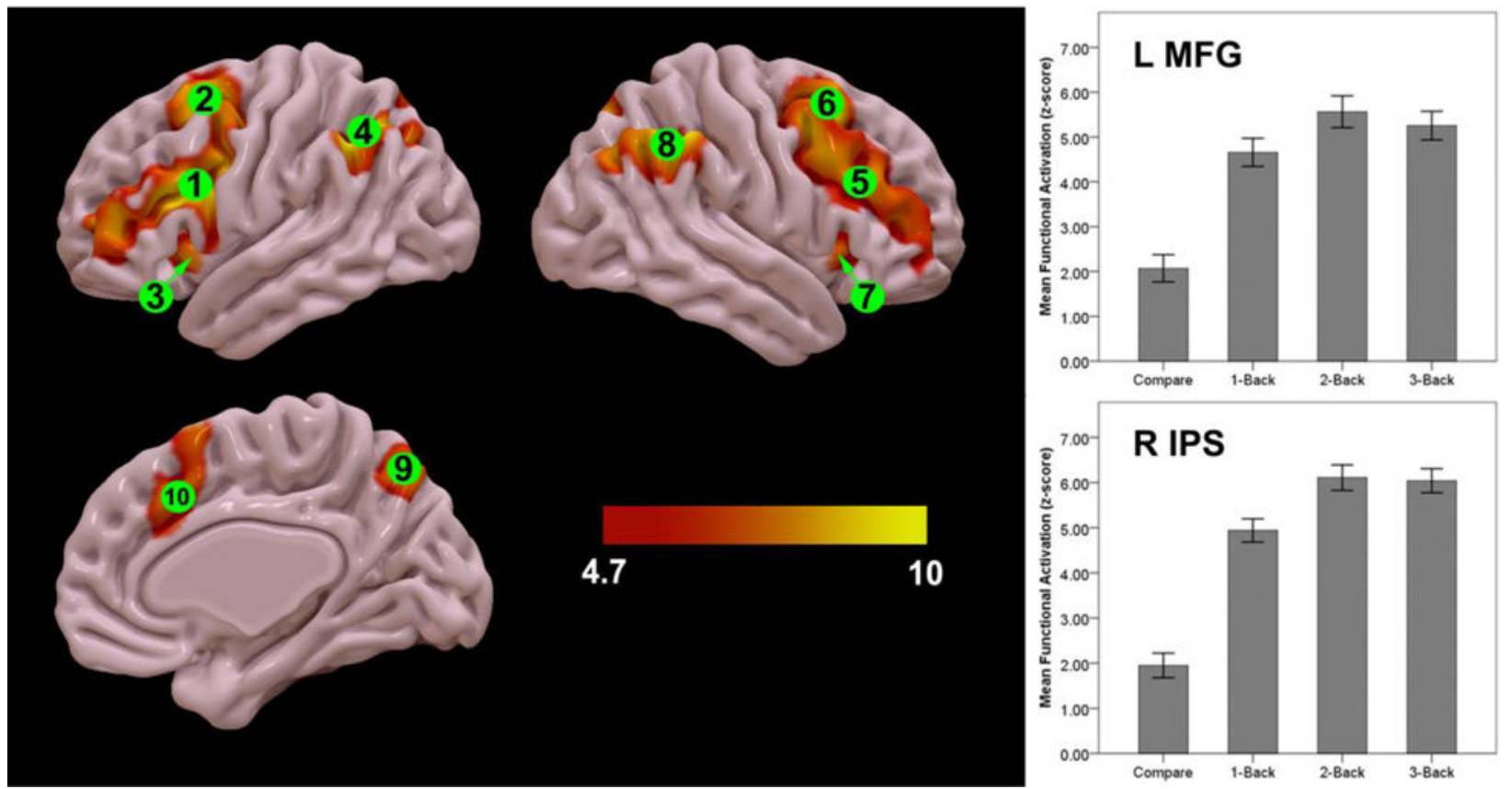

Figure 3. Regions Showing Significant Linear Increase in Functional Activation over Levels of NBack Difficulty

(LEFT) Significant increases in functional activation magnitude were observed throughout frontal and parietal cortices. Green numbered circles indicate location of ROIs isolated for subsequent analyses. (RIGHT) ROI patterns of functional activation across N-Back task conditions across all participants. A similar pattern of activation to that depicted here for the L MFG and R IPS was observed across all 10 regions selected for further analysis. L MFG = left middle frontal gyrus; R IPS = right intraparietal sulcus. Numbering of ROIs in Figure match numbering in Table 1. 


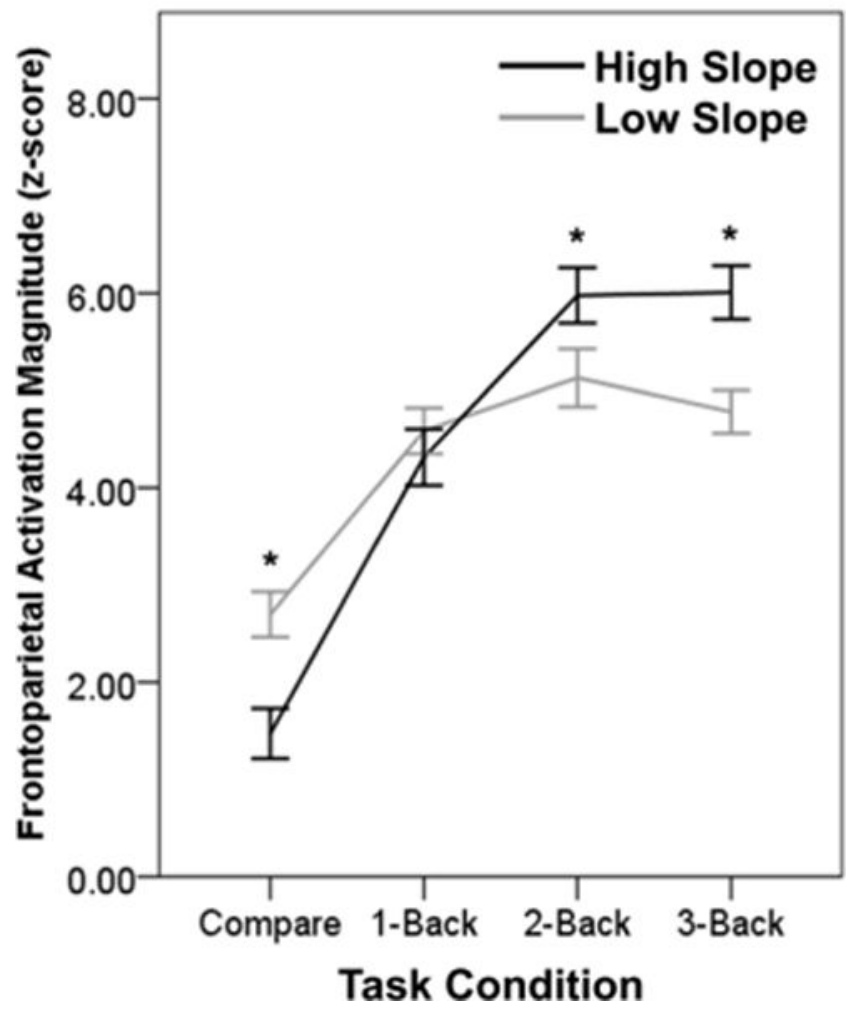

Figure 4. Frontoparietal Activation Magnitude by N-Back Task Condition Individuals with lower modulation range showed generally higher levels of activation during the lowest level of task demand and lower levels of activation during the highest levels of task demand. 
(A)

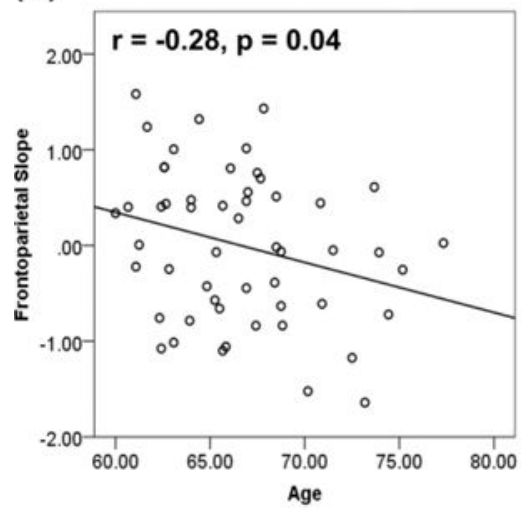

(B)

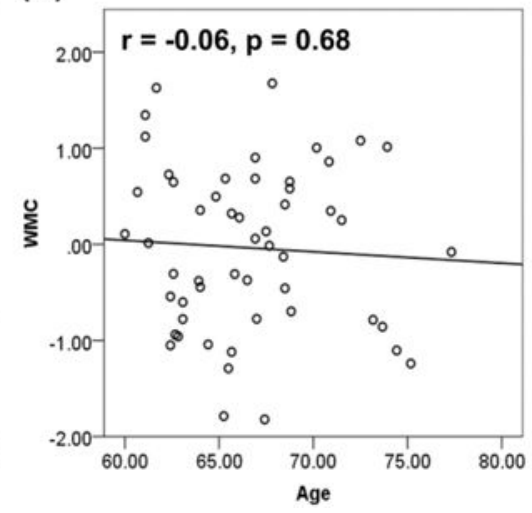

(C)

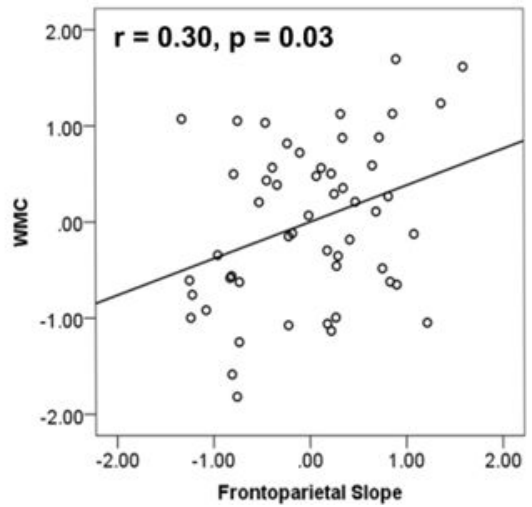

Figure 5. Relationships between Frontoparietal Slope, Age, \& WMC (A) Age was negatively associated with Frontoparietal Slope. (B) Age was not significantly associated with WMC. (C) Individual differences in Frontoparietal Slope significantly predicted WMC even after controlling for Age and mean functional activation magnitude. 


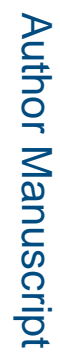

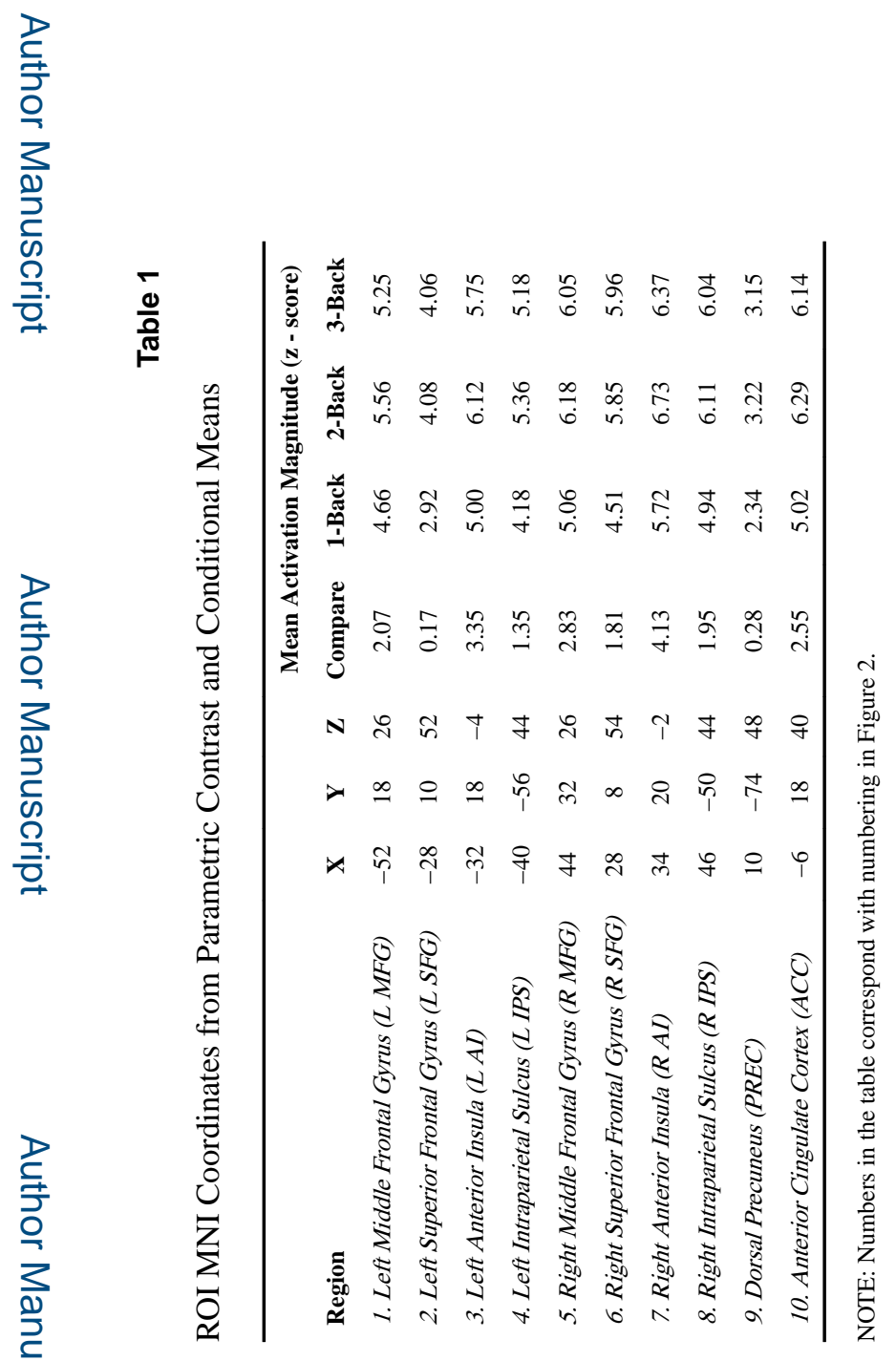

Brain Cogn. Author manuscript; available in PMC 2018 November 01. 